\title{
Pattern of specific dermatoses of pregnancy: a hospital based study
}

\author{
R. Indradevi ${ }^{1 *}$, P. Oudeacoumar ${ }^{1}$, Laxman Besra $^{1}$, V. Anitha ${ }^{2}$
}

\author{
${ }^{1}$ Department of DVL, Aarupadai Veedu Medical College and Hospital, Kirumampakkam, Pondicherry, India \\ ${ }^{2}$ Department of O \& G, Aarupadai Veedu Medical College and Hospital, Kirumampakkam, Pondicherry, India
}

Received: 29 August 2015

Revised: 15 September 2015

Accepted: 28 October 2015

\author{
*Correspondence: \\ Dr. R. Indradevi, \\ E-mail: drindradevi@rediffmail.com
}

Copyright: ( $)$ the author(s), publisher and licensee Medip Academy. This is an open-access article distributed under the terms of the Creative Commons Attribution Non-Commercial License, which permits unrestricted non-commercial use, distribution, and reproduction in any medium, provided the original work is properly cited.

\begin{abstract}
Background: The specific dermatoses of pregnanc represent a heterogenous group of ill-defined pruritic skin diseases related specifically to pregnancy and/or the immediate postpartum period. The objective of the study is to determine the patterns of specific dermatoses of pregnancy in a tertiary care hospital.

Methods: A total of 450 pregnant females, irrespective of their parity and gestational age were screened for various pruritic skin conditions and those with specific pregnancy dermatoses were identified and evaluated.

Results: The age of the study population ranged from 18 to 36 years (mean age 24 years). The study population included $261(58 \%)$ primigravidae and $189(42 \%)$ multigravidae. Seventeen (3.77\%) pregnant females had specific dermatoses of pregnancy. Out of these, $9(52.94 \%)$ had pruritic urticarial papules and plaques of pregnancy (PUPPP), followed by pruritic folliculitis of pregnancy in $5(29.41 \%)$, pruritic gravidarum in $2(11.76 \%)$ and pemphigoid gestationis in $1(5.88 \%)$. PUPPP was the commonest specific dermatoses noted in our study.

Conclusions: The present study highlights the pattern of specific dermatoses of pregnancy in our hospital. Early diagnosis of specific dermatoses of pregnancy may prevent harmful effect on mother and fetus. The pruritic eruptions of pregnancy, which are not a rare entity can be a source of significant distress to the pregnant female and need timely therapeutic intervention.
\end{abstract}

Keywords: Specific dermatoses, Pregnancy, PUPPP

\section{INTRODUCTION}

The specific dermatoses of pregnancy is a group of disorders often characterized by severe itching with skin lesions of varying morphology, occurring exclusively during pregnancy and post partum period.

The complex endocrinologic, immunologic, metabolic and vascular changes associated with pregnancy may influence the skin in various ways.

Mechanisms leading to pregnancy specific dermatoses may be a reflection of the hormonal and immunological changes associated with pregnancy that may potentially pose a serious risk to the fetus such as prematurity and low birth weight.
They have been classified as polymorphic eruption of pregnancy (syn. Pruritic urticarial papules and plaques of pregnancy) (PUPPA), intrahepatic cholestasis of pregnancy (ICP), pemphigoid gestationis (PG) and atopic eruption of pregnancy (AED).

Familiarity with the clinical presentation of these diseases is essential, as unequivocal diagnostic tests are available only for PG and ICP and a pregnant patient with pruritis needs information on her condition, as well as the associated fetal risks. Our purpose was to find the pattern of specific dermatoses of pregnancy in a tertiary care hospital. 


\section{METHODS}

The study was conducted on pregnant females attending the out-patient department of obstetrics and gynaecology of Aarupadai Veedu Medical College and Hospital over a period of 1 year. A written informed consent was taken from all the patients before the study. A total of 450 pregnant females attending the out-patient department of the above mentioned hospital for routine obstetrics checkup were enrolled in the study and screened for the presence of any dermatological complaints. A detailed history including demographic data, parity, chief dermatological complaints, onset in relation to the duration of pregnancy, presence of itching, history of atopy, jaundice, similar complaints in previous pregnancy, family history, exacerbating factors, associated medical or skin disorders was elicited.

General physical, systemic and complete cutaneous examination was carried out in all patients. In patients presenting with specific dermatoses of pregnancy, the morphology and distribution of lesions was recorded. The presence of any co-incident dermatoses developing during pregnancy was studied. Routine investigations including complete blood count, liver function tests, kidney function tests and urine examination were carried out in all patients. Relevant bedside laboratory procedures such as Tzanck smear, KOH mount etc, were carried out. Total serum immunoglobulin E ( $\mathrm{IgE}$ ) levels and total serum bile acid levels were measured wherever deemed necessary.

\section{RESULTS}

A total of 450 pregnancy females were involved in our study for a period of 1 year. Out of these, 261 (58\%) were primigravidae \& 189 (42\%) were multigravidae. Their age range was 18-36 years with a mean of 24 years. Most of them presented in third trimester 306 (68\%), few in second trimester $144(32 \%) \&$ none in the first trimester.

Seventeen $(3.77 \%)$ pregnant female had specific dermatoses of pregnancy. Among the specific dermatomes of pregnancy, $9(52.94 \%)$ had PUPPP, followed by pruritic folliculitis of pregnancy in 5 $(29.41 \%)$, pruritic gravidarum in $2(11.76 \%)$ and pemphigoid gestationis in $1(5.88 \%)$ (Table 1$)$.

PUPPP was the commonest specific dermatoses noted in our study. It was observed in $9(52.94 \%)$ cases. All were primigravidae. All were single gestational pregnancies. The eruption started in the third trimester of pregnancy in all the cases. In 7 out of 9 patients $(78 \%)$, eruptions started over the anterior abdominal wall often closely following the lines of striae, and in remaining 2 (22\%), eruption developed in upper thighs first (Figure 1).

Pruritic folliculitis was noted in $5(29.41 \%)$. Of these $3(60 \%)$ were primigravidae, $2(40 \%)$ were multigravidae. History of atopy noted in 2 cases (40\%). 1(50\%) out of 2 multigravidae gave history of similar lesions in previous pregnancy. In all cases, the eruptions predominantly involved the extremities. In $4(80 \%)$ cases, the eruptions started during the second trimester and in $1(20 \%)$ case, the eruptions started during the third trimester. Serum IgE level was raised in $1(20 \%)$.

ICP occurred in 2 cases $(11.76 \%)$. Out of these, $1(50 \%)$ was primigravida, and another $1(50 \%)$ was multigravida. All presented with pruritus as the presenting complaint. All cases of ICP started during the third trimester of pregnancy. One $(50 \%)$ case reported identical symptoms in the previous pregnancy. Family history of similar complaints during pregnancy could be elicited in 1 case. Jaundice with raised alkaline phosphatase was noted in $1(50 \%)$ case. Hepatitis serology was negative in all cases.

Table 1: Frequency distribution of specific dermatoses of pregnancy in the study.

\begin{tabular}{|ll|}
\hline $\begin{array}{l}\text { Specific dermatoses of } \\
\text { pregnancy }\end{array}$ & Number (\%) \\
\hline $\begin{array}{l}\text { Pruritic Urticarial Papules and } \\
\text { Plaques of Pregnancy (PUPPP) }\end{array}$ & $9(52.94 \%)$ \\
\hline Pruritic folliculitis (AEP) & $5(29.4 \%)$ \\
\hline $\begin{array}{l}\text { Intrahepatic cholestasis of } \\
\text { pregnancy (ICP) }\end{array}$ & $2(11.78 \%)$ \\
\hline Pemphigoid gestationis (PG) & $1(5.88 \%)$ \\
\hline
\end{tabular}

$\mathrm{PUPPP}=$ Pruritic urticarial papules and plaques of pregnancy, $\mathrm{AEP}=$ Atopic eruption of pregnancy, $\mathrm{ICP}=$ Intrahepatic cholestasis of pregnancy, $\mathrm{PG}=\mathrm{Pemphigoid}$ gestationis.

Table 2: Distribution of specific dermatoses of pregnancy in different age periods (number $=17$ ).

\begin{tabular}{|lcccc|}
\hline $\begin{array}{l}\text { Age } \\
\text { groups } \\
\text { (years) }\end{array}$ & $\begin{array}{c}\text { PUPPP } \\
(\mathrm{n}=9)\end{array}$ & $\operatorname{AEP}(\mathbf{n}=5)$ & $\mathrm{ICP}(\mathrm{n}=2)$ & $\mathrm{PG}(\mathrm{n}=1)$ \\
\hline $18-20$ & 1 & 2 & 1 & 1 \\
\hline $21-25$ & 3 & 2 & 1 & \\
\hline $26-30$ & 2 & 1 & & \\
\hline $31-35$ & 2 & & & \\
\hline $36-40$ & 1 & & & \\
\hline
\end{tabular}

$\mathrm{PUPPP}=$ Pruritic urticarial papules and plaques of pregnancy, $\mathrm{AEP}=$ Atopic eruption of pregnancy, $\mathrm{ICP}=$ Intrahepatic cholestasis of pregnancy, $\mathrm{PG}=\mathrm{Pemphigoid}$ gestationis.

Table 3: Distribution of specific dermatoses of pregnancy during different trimesters.

\begin{tabular}{|ccccc|}
\hline Trimester & PUPPP & AEP & ICP & PG \\
$\begin{array}{c}1^{\text {st }} \\
\text { trimester }\end{array}$ & - & - & - & - \\
\hline $\begin{array}{c}2^{\text {nd }} \\
\text { trimester }\end{array}$ & - & $4(80 \%)$ & - & - \\
\hline $\begin{array}{c}3^{\text {rd }} \\
\text { trimester }\end{array}$ & $9(100 \%)$ & $1(20 \%)$ & $2(100 \%)$ & $1(100 \%)$ \\
\hline
\end{tabular}

$\mathrm{PUPPP}=$ Pruritic urticarial papules and plaques of pregnancy, $\mathrm{AEP}=$ Atopic eruption of pregnancy, $\mathrm{ICP}=$ Intrahepatic cholestasis of pregnancy, $\mathrm{PG}=\mathrm{Pemphigoid}$ gestationis. 
One $(5.88 \%)$ case of PG was seen in this study (Figure 2). Patient was a primigravida. Patient started with itchy, urticarial lesions over the abdomen during the third trimester, which was followed by a generalised bullous eruption. Palms, soles and mucosae were spared (Table 2 and 3).

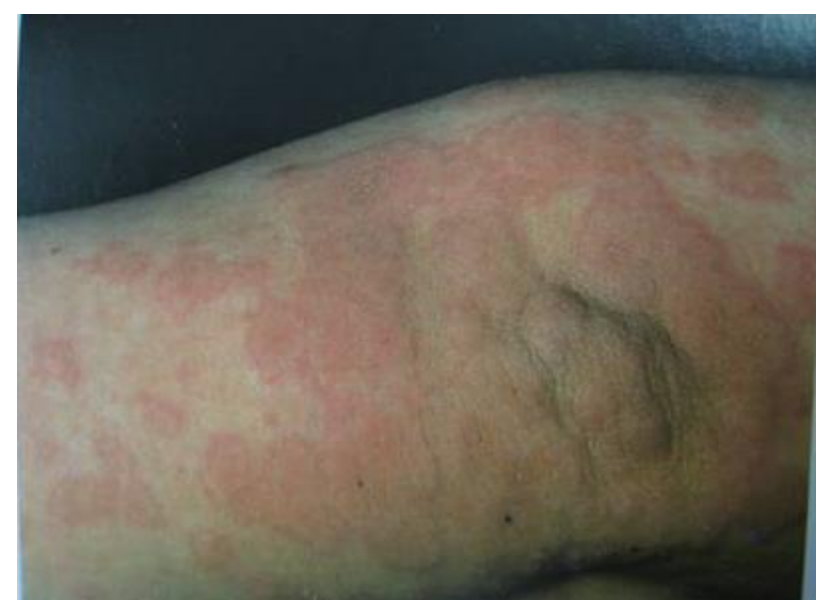

Figure 1: Pemphigoid gestationis early stage.

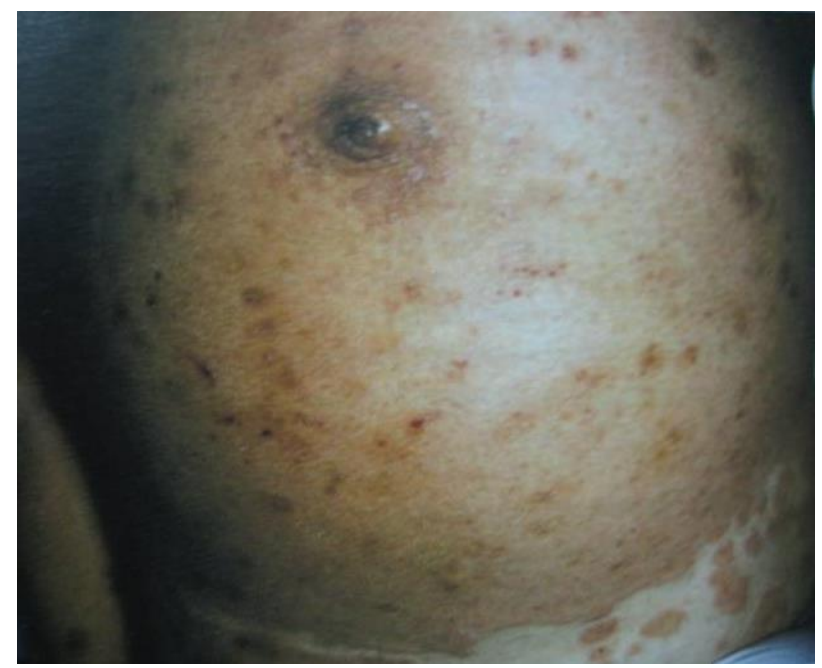

Figure 2: Pemphigoid gestationis bullous stage.

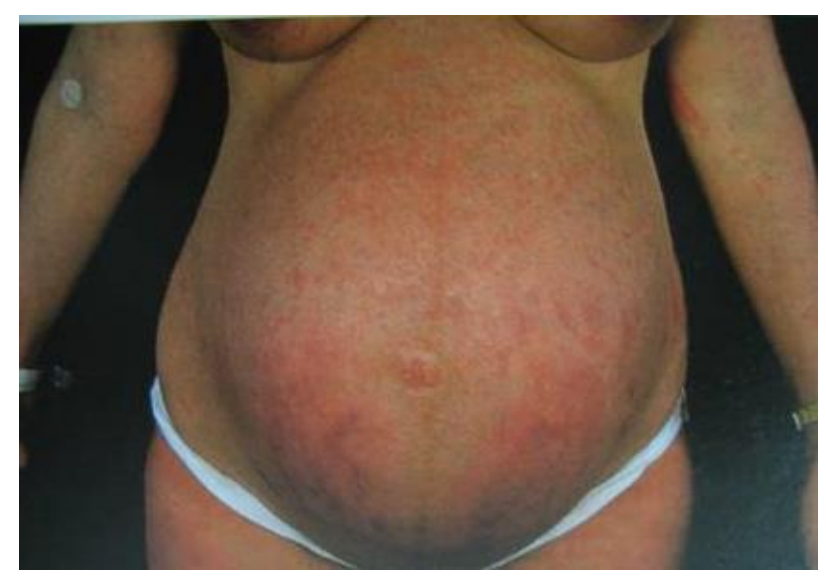

Figure 3: PUPPP on abdomen.

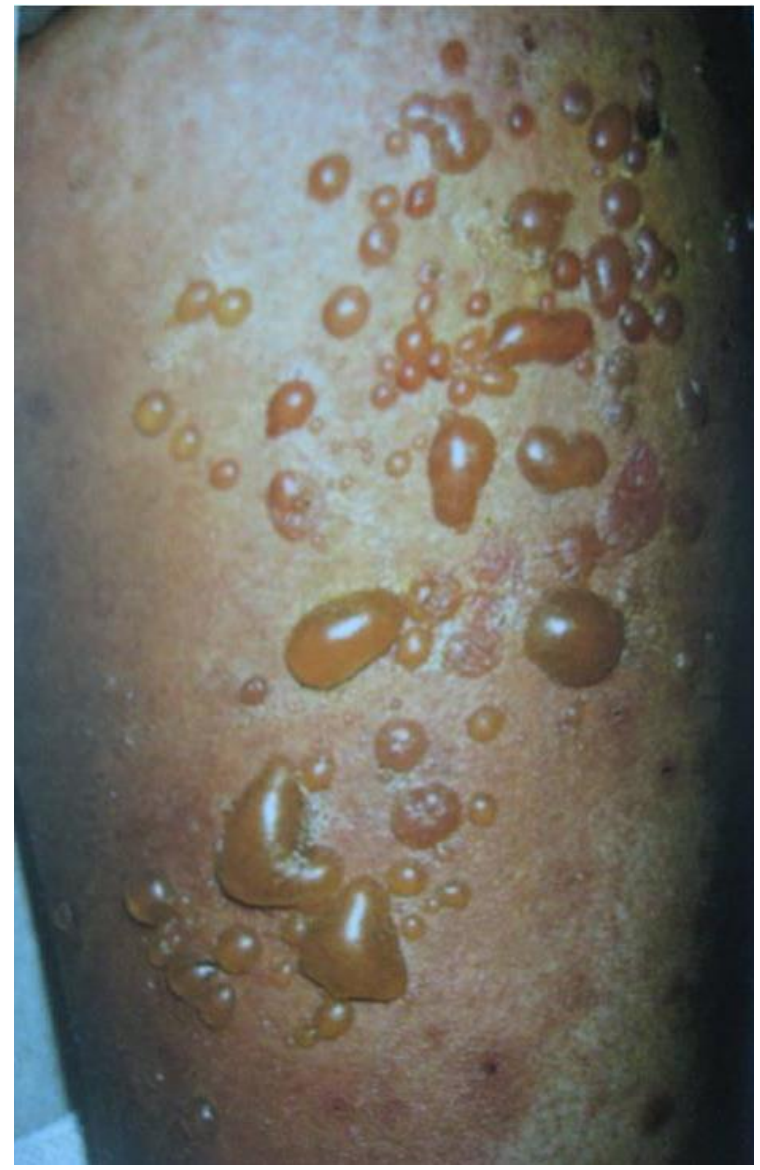

Figure 4: PUPPP on limb.

\section{DISCUSSION}

Pregnancy specific skin dermatoses includes an illdefined, heterogenous group of pruritic skin eruptions, which are seen only in pregnancy. ${ }^{1}$

The classification of specific pregnancy dermatoses were given by so many authors such as Holmes \& Black in 19832 and Shornick in 19983. The most recent rationalised classification has been proposed by Ambros Rudolph et $\mathrm{al}^{4}$ in 2006 which is as follows:

1. Polymorphic light eruption of pregnancy (pruritic urticarial papules and plaques of pregnancy).

2. Atopic eruption of pregnancy (Eczema of pregnancy, prurigo of pregnancy, pruritic folliculitis of pregnancy).

3. Pemphigoid gestationis (PG).

4. Intrahepatic cholestasis of pregnancy (ICP).

The incidence of these specific dermatoses of pregnancy ranges from $0.5-3 \% .^{5}$ In our study comprising of 450 cases, PSDs were seen in $17 / 450$ cases $(3.77 \%)$ which is comparable to the study done by Kumari et al. ${ }^{6}$

PUPPP was the most common specific dermatoses of pregnancy in our study. It was observed in 9/17 cases $(52.94 \%)$. The results are similar to those encountered in Roger et al, Beckett \& Goldberg, ${ }^{7}$ Elling et al \& Reed. ${ }^{8}$ 
Intensely pruritic papules within striae distensiae were found on abdomen, in some patients on the trunk, extremities as well. It occurs classically in primigravidae during the third trimester of pregnancy or occasionally postpartum and does not usually recur in subsequent pregnancies. Incidence of PEP is higher in multiple pregnancies. All the affected patients in our study were primi-gavidae and all were single gestation pregnancies.

The development of pruritic folliculitis was noted in 5 $(29.41 \%)$ cases. Pruritic excoriated papules were seen on extensors. All the cases were seen in third trimester. The results are similar to those encountered in Puri \& Puri study. ${ }^{9}$

Prurigo gravidarum (intrahepatic cholestasis of pregnancy) was observed in 2 cases $(11.76 \%)$ out of 14 cases. Incidence of ICP is reported at 1 in 100 pregnancies10. ICP occurs due to a mild form of intrahepatic bile secretory dysfunction. It is seen in the third trimester of pregnancy in about $70 \%$ of cases. ${ }^{11}$ In our study also, it is noted in third trimester. Recurrences in subsequent pregnancies occur in many patients.

There was a single (5.88\%) case of Pemphigoid gestationis (PG) in our study. PG is a rare autoimmune bullous disease of pregnancy with incidence of 1 in $10000-1$ in 50000 pregnancies. ${ }^{12}$ The disease is probably triggered by placental antigens that cross react with skin antigens. ${ }^{13}$ It often recurs in subsequent pregnancies appearing earlier in gestation and in more severe forms. ${ }^{14}$ The condition is characterised by sudden onset of intensely pruritic urticarial lesions usually over the abdomen followed by development of a generalised bullous eruption with relative sparing of face, mucous membranes, palms \& soles. $^{15}$ Our patient was a primigravida. She has to be followed carefully in subsequent pregnancies.

\section{CONCLUSIONS}

Physiological skin changes in pregnancy are quiet common. However the specific pregnancy dermatoses, which are not a rare entity, are distinguished for better patient care as they are the source of significant distress to the pregnant female \& need timely therapeutic intervention.

Funding: No funding sources Conflict of interest: None declared

Ethical approval: The study was approved by the Institutional Ethics Committee

\section{REFERENCES}

1. Kroumpouzos G, Cohen LM. Dermatoses of pregnancy. J Am Acad Dermatol. 2001;45:1-19.

2. Holmes RC, Black MM. The specific dermatoses of pregnancy: A reappraisal with special e mphasis on a proposed simplified clinical classification. Clin Exp dermatol. 1982;7:65-73.

3. Shornick JK. Dermatoses of pregnancy. Semin Cutan Med Surg. 1998;17:172-81.

4. Ambros - Rudolph CM, Mullegger RR, VaughanJones SA, Kerl H, Black MM. The specific dermatoses of pregnancy revisited and reclassified: Results of a retrospective two-center study on 505 pregnant patients. J Am Acad Dermatol. 2006;54:395-404.

5. Roger D, Vaillant L, Fignon A, Pierre F, Bacq Y, Brechot JF, et al. Specific pruritic diseases of pregnancy. A prospective study of 3192 pregnant women. arch dermatol. 1994;130;734-9.

6. Kumari R, Jaisankar TJ, Thappa DM. A clinical study of skin changes in pregnancy. Indian $\mathrm{J}$ Dermatol Venereol Leprol. 2007;73:141.

7. Becket MA Goldberg NS. Pruritic urticarial papules \& plaques of pregnancy \& skin distension. Arch Dermato. 1994;130:824-9.

8. Elling SV, MC Kenn Powel FC. Pruritic urticarial papules and plaques of pregnancy in twin \& triplet pregnancies. J Eur Acad Dermatol Venereol. 2000;14:378-81.

9. Puri N, Puri A. A Study of dermatoses of pregnancy. Our dermatol online. 2013;4:56-60.

10. Lammert F, Marshall HU, Glantz A, Matern S. Intrahepatic cholestasis of pregnancy: Molecular pathogenesis, diagnosis and management. J Hepatol. 2000;33:1012-21.

11. Adlercreutz $\mathrm{H}$. Itching in pregnancy. $\mathrm{Br}$ Med $\mathrm{J}$. 1975;3:608.

12. Intong LR, Murrell DF. Pemphigoid gestationis: pathogenesis and clinical features. Dermatol Clin. 2011;29:447:52.

13. Sachdeva $\mathrm{S}$. The dermatoses of pregnancy. Indian $\mathbf{J}$ dermatol.2008;53:103-5.

14. Massod S, Rizvi DA, Tabassum S, Akhtar S, Alvi RU. Frequency and clinical variants of specific dermatoses in third trimester of pregnancy: A study from tertiary care centre. J Pak Med Assoc. 2012;62:244-8.

15. Shimanovich I, Skrobek C, Rose C, Nie Z, Hashimoto T, Brocker EB, et al. Pemphigoid gestationis with predominant involvement of oral mucous membranes and $\operatorname{IgA}$ autoantibodies targeting the C-terminus of BP180. J Am Acad Dermatol. 2002;47:780-4.

Cite this article as: Indradevi R, Oudeacoumar $\mathrm{P}$, Besra L, Anitha V. Pattern of specific dermatoses of pregnancy: a hospital based study. Int J Reprod Contracept Obstet Gynecol 2015;4:1817-20. 